\title{
Leibniz ON THE EXPRESSION OF GoD
}

\author{
STEWART DUNCAN \\ Department of Philosophy, University of Florida
}

\begin{abstract}
Leibniz frequently uses the notion of expression, but it is not easy to see what expression is. This paper focuses on the case of the expression of God, which is prominent in the Discourse on Metaphysics. Leibniz says there that finite substances express God. That talk of expression seems not to fit with standard understandings of expression as involving isomorphism, or at least a structural similarity of the expressing thing and the expressed one. Beyond that general puzzle, the treatment of expression of God in the Discourse suggests several questions. Which substances did Leibniz believe expressed God? Why did Leibniz believe those substances expressed God? And did he believe that all substances expressed God in the same way and for the same reasons? In answering those questions, this paper distinguishes two views about expression in the Discourse; considers Leibniz's reasons for holding that substances express their causes, and for thinking that minds have a particular similarity to God; and argues that Leibniz's views about emanative causation may be helpful for understanding the unity of his apparently distinct views here.
\end{abstract}

L

EIBNIZ makes frequent use, in his philosophy, of the notion of expression. He uses it, for example, in giving his definition of perception as the expression of a multitude in a simple. ${ }^{\mathrm{I}}$ Expression itself appears to be some sort of representation relation. Beyond that, however, it is rather less clear what expression is.

Looking at Leibniz's texts, there appears to be a repeated requirement that, for there to be expression, there must be a regular relation between the expressing thing and the thing expressed. ${ }^{2}$ It remains unclear, however, what this requirement amounts to. As a result, there has been a certain amount of debate in recent literature about what the standards for a 'regular relation' are. In this debate one finds repeatedly the suggestion that Leibniz requires the expressing thing to be isomorphic with the expressed. This is countered by the thought that, taken strictly,

I. For example: "perception is the expression of a multitude in a unity" (G: 3, 69/WF: I 30$)$.

2. For an early version of this notion, and some examples, see "What is an Idea?" (A: 6.4, I369-7I/L: 207-8) 
that is too strong a requirement. Nevertheless, there remains the suggestion that expression is something like isomorphism, in that it requires a structural similarity between the thing expressing and the thing expressed. ${ }^{3}$

That sort of view derives some of its support from the 'regular relation' passages, and further support from some of Leibniz's frequent examples of expression. Cases such as an ellipse expressing a circle, or even a map expressing a piece of land, seem to fit well with this understanding of expression. There are, however, a variety of other cases in which Leibniz says expression is present. ${ }^{4}$ Leibniz also talks about speech expressing thought, about an equation expressing a figure, about substances expressing the universe, about substances expressing God, and about God expressing "everything at once, the possible and the actual, past, present, and future" (WF: II 8). 5 Though it may perhaps be possible to understand all these cases as involving the same relation of expression that is seen in the case of the circle and the ellipse, it is far from obvious that this is the case. Indeed one might suspect that there is no overall account of expression that can really capture all the cases. ${ }^{6}$

I focus in this paper on the curious case of the expression of God.7 Leibniz says that created substances express God, or something closely related to God, such as his resolution to create the world. ${ }^{8}$ What does Leibniz mean by saying that a substance expresses God? In addressing that question I consider, in particular, the I 686 Discourse on Metaphysics, where Leibniz puts the notion of expression to multiple uses. First, substances are said to express the entire universe. Secondly, expression is used to explain the action of one substance on another. Thirdly, expression is invoked in explaining the distinction between the miraculous and the natural. Fourthly, expression is used in explaining Leibniz's theory of ideas. And fifthly, Leibniz proposes a view-or perhaps two distinct views-about created substances' expression of God. Thus the Discourse illustrates the importance-and also the apparent flexibility — that the notion of expression had for Leibniz, at least at some times.

3. For these discussions, see McRae (I976: 20-6), Kulstad (I977), Mates (I986: 37-9), Rutherford (I995: 38-9), Swoyer (I995), Simmons (200I: 4I-2), Perkins (2004: 79-8I), Puryear (2006: 8-I6), Kulstad (2006), and Bolton (20I I: I3 8-40).

4. Kulstad (1977: 57) provides a useful table of Leibniz's examples of expression.

5. This remark comes from Leibniz's "Reply to the Comments on the Second Edition of M. Bayle's Critical Dictionary, in the Article 'Rorarius', Concerning the System of Pre-established Harmony". There is a version of this at (G: 4, 554-7I), but WF translates the somewhat different original version from the I716 Histoire critique de la République des lettres.

6. See Sleigh (I990: I74) and Garber (2009: 216).

7. This has been relatively little discussed in the recent secondary literature on expression, but see Nelson (2005), and also the discussion by Perkins (2004: 83-87) of expression of necessary truths.

8. There is some question as to whether he thought that all, or only some, of the created substances did this. This is discussed below. 
In discussing the expression of God in particular, the Discourse is an important text to consider because it contains several apparently different strands of thinking on the topic: here we seem to find both the thought that all substances express God, and also the thought that only some substances, minds, do; both the thought that substances express God because God is their cause, and the thought that substances express God because they are made in God's image. These apparently different views point to further questions. First, which substances did Leibniz believe expressed God? Secondly, why did Leibniz believe those substances expressed God? And thirdly, did he believe that all substances expressed God in the same way and for the same reasons-or, alternatively, did he tell different stories about different types of substances??

\section{Central Texts}

The notion of the expression of God appears in three places in the Discourse: in DM I 5-6, in DM 26-30, and in DM 35-6.

\section{I.I. DM I 5-6}

DM I 5 aims principally to present a theory of one substance's action on another, or at least of when it can be said that one substance acts on another. This sense of action is explained in terms of expression. As the section summary puts it, "The Action of One Finite Substance on Another Consists Only in the Increase of Degree of its Expression Together with the Diminution of the Expression of the Other, Insofar as God Requires Them to Accommodate Themselves to One Another". Leibniz's story is that when we would usually say that one substance acts on another, what actually happens, speaking more metaphysically correctly, is that the 'acting' substance increases its degree of expression, while the other decreases its. God coordinates all of this, so the changes correspond appropriately with one another. But what is this expression that changes?

The efficacy [vertu] a particular substance has is to express well the glory of God, and it is by doing this that it is less limited. And whenever something exercises its efficacy or power, that is, when it acts, it improves and extends itself insofar as it acts. Therefore, when a change takes place by which several substances are affected (in fact every change affects all of them), I believe one may say that the substance which immediately passes

9. Grosholz (200I) discusses the role of expression in the Discourse under the description "theomorphic expression". However, where I focus on finite substances' expression of God, Grosholz focuses on their being like God by expressing other things. 
to a greater degree of perfection or to a more perfect expression exercises its power and acts, and the substance which passes to a lesser degree shows its weakness and is acted upon [pâtit] (DM I 5 ).

Here the degree of expression is apparently equated with a degree of perfection. To act, and increase one's expression, is also to acquire a higher degree of perfection. ${ }^{\text {Io }}$ This is all connected to expression of one particular thing, the glory of God. So to act is, it appears, to express more perfectly the glory of God, and to be acted upon is to express it less perfectly. Thus DM I 5 is not merely an account of the coordinated changes of created substances in the pre-established harmony. It also connects the changes of substances to the expression of the divine, in this case of the glory of God. ${ }^{\text {II }}$

Such connections are made again in DM I6, which distinguishes the miraculous from the natural. The summary of that section offers another example of something expressed: "God's Extraordinary Concourse Is Included in That Which Our Essence Expresses". And the section itself tells us both that "an effect always expresses its cause and God is the true cause of substances" and that "our essence ... expresses our union with God himself".

\section{I.2. DM 26-30}

The language of expression of God occurs again in a series of sections that apparently focus on discussion of Malebranche's views. These sections begin with DM 23, where Leibniz announces that he will discuss ideas, and whether we see all things in God. ${ }^{\mathrm{I} 2}$ Within this discussion, the notion that our soul expresses God occurs repeatedly. Thus Leibniz says in DM 26 that "our soul expresses God, the universe, and all essences, as well as all existences". Such language occurs again in DM 28 and DM 29.

Iо. There are several other passages in which Leibniz gives similar accounts of activity. They do not all invoke the divine in this way. See, for example, the brief discussion of this issue in Kulstad \& Carlin (2013), or the longer discussion of Garber (2009: 206-24).

II. One might perhaps suggest that a substance expresses the glory of God by expressing the universe God has created. (Consider DM 9: "the universe is in some way multiplied as many times as there are substances, and the glory of God is likewise multiplied by as many entirely different representations of his work".) If that were so, expressing the glory of God would not require expressing God. This deflationary reading would reduce the number of examples of expression of God in the Discourse, but would not change the overall picture: Leibniz says repeatedly that substances express God.

I2. I am using this just as a characterization of these particular sections. There is a broader question of whether the Discourse as a whole is intended as a criticism of Malebranche. On this see for example Jolley (2004). 
Thus we have ideas of everything in our soul only by virtue of God's continual action on us, that is to say, because every effect expresses its cause, and thus the essence of our soul is a certain expression, imitation or image of the divine essence, thought, and will, and of all the ideas comprised in it (DM 28).

In my opinion, this arises from the fact that they have not yet considered sufficiently either what we have just explained about substances or the full extent and independence of our soul, which makes it contain everything that happens to it, and makes it express God and, with him, all possible and actual beings, just as an effect expresses its cause (DM 29).

Leibniz appears here to be focused on the human soul, rather than substances in general. Thus what is said here appears to differ from the earlier claim in DM I 5 that every substance expresses the glory of God. Some continuity is provided by the claim that every substance expresses its cause, and God is the cause of every substance, which had occurred in DM I6, and is echoed in DM 28 and 29. Meanwhile, the notion that we are imitations or images of God is explicitly connected here to our expressing God-unlike in its previous occurrence in DM 9, where Leibniz talks about imitation of God, and expression of the universe, but not expression of God. So there appears to be a good deal of complexity to the theory by this point.

\section{I.3. DM $35-6$}

The notion of the expression of God returns later in the Discourse, in DM 35-6. These sections are in a part of the Discourse, which we might see as running from $\mathrm{DM}_{32}$ to the end in DM 37, in which Leibniz discusses minds and their relationship to God. In both DM 35 and DM 36 Leibniz is concerned to explore the ways in which minds differ from other substances. At times he puts the point in terms of expression.

The Excellence of Minds and That God Considers Them Preferable to Other Creatures. That Minds Express God Rather Than the World, but That the Other Substances Express the World Rather Than God (DM 35 summary).

For certainly minds are the most perfect beings and best express divinity. And since the whole nature, end, virtue, and function of substance is merely to express God and the universe, as has been sufficiently explained, there is no reason to doubt that the substances which express the universe with the knowledge of what they are doing and which are capable of knowing great 
truths about God and the universe, express it incomparably better than do those natures, which are either brutish and incapable of knowing truths or completely destitute of sensation and knowledge (DM 35 ).

In this way we may say that, although all substances express the whole universe, nevertheless the other substances express the world rather than God, while minds express God rather than the world (DM 36 ).

Whether the central idea is that minds are better than other substances at expressing God, or that only minds can express God and other substances cannot, is not immediately obvious here. But clearly Leibniz is saying something in that general area.

Before moving on to more detailed interpretive discussions, it is worth emphasizing that the notion of the expression of God occurs repeatedly, in several contexts, and appears to be asked to do a decent amount of work. It is not, at least in the Discourse, a mere trivial detail, but something that Leibniz appears to find rather important. For all that, it is not clear just what the notion is, or just how Leibniz thinks this expression works. I have tried to indicate some of the puzzles above. There are certainly others.

\section{Expression of Causes}

\section{I. A Causal Argument for Expression of God}

Why, according to Leibniz, does any substance express God? Well, DM I 6 tells us that "an effect always expresses its cause and God is the true cause of substances". Given that, we can construct the following argument.

I. An effect always expresses its cause.

2. Every substance is an effect of God. So

3. Every substance expresses God.

Similarly, Leibniz wrote in August I 686 to Simon Foucher that "Each effect expresses its cause, and the cause of each substance is the decision which God took to create it" (A: 2.2, 9I/WF: 53). That suggests a slight variant on the above argument.

I. An effect always expresses its cause.

$2 *$. Every substance is an effect of God's decision to create it. So

$3 *$. Every substance expresses God's decision to create it. 
One difference between these two arguments concerns what we should take the relata of expression - and indeed of causation - to be. Are these relations between substances, or other things, such as decisions?. ${ }^{\text {I3 }}$ But there is a clear common core to the two arguments. All substances express their causes, and all substances are caused by God, so all substances express God. ${ }^{\text {I4 }}$

This is a claim about all substances. ${ }^{15}$ As we have seen above, and as I shall discuss below, in places Leibniz appears to say that only some substances express God. But not only do these passages state the opposite, they also state an argument that makes it hard to restrict expression of God to merely some of the substances in the world. ${ }^{16}$ For every substance was created by God, not just some substances.

I discuss the claim that only some substances express God further in section 3 below: it appears that a second sort of argument for expression, and indeed a second sort of expression, is at work in those other passages. For now, however, I consider the reasons for premise I above. Why think that substances express their causes?

\subsection{Why Think That Substances Express Their Causes?}

Given a standard reading of expression as involving, or just being, a sort of structural similarity, it is hard to understand why substances must express their causes.

I3. Although I have been talking of substances expressing God, the texts give a variety of different, though related, relata to this expression relation. The thing expressing varies: a substance, our essence, our soul, a mind. The thing expressed varies just as much: God, the glory of God, God's extraordinary concourse, our union with God, the divine essence, God's decision to create the expressing substance, and "God and, with him, all possible and actual beings" (DM 29). Elsewhere we find Leibniz talking circa I680 of minds [les esprits] expressing "the perfection of their creator" ("Conversation du Marquis de Pianese et du Pere Emerey Emerite", A: 6.4, 227I; on dating see A: $6.4,224 \mathrm{I})$. Because Leibniz presents these claims in very similar ways, there is a temptation to take him always to be talking about the same thing, about some created substance or other expressing God. But we should be alert to the possibility that there is more going on: e.g., that the expression of the glory of God is a significantly different thing from the expression of God's resolution to create a substance. That said, the expressing thing is almost always a substance, so perhaps we should be inclined to take the expressed one to be a substance too, and thus to be God rather than any feature of God.

I4. Related is the comment in the I689 "Primary Truths" that "all individual created substances are different expressions of the same universe and different expressions of the same universal cause, namely God" (A: 6.4, I646/AG: 33). Though this does not explicitly say that the expression is present because of the causation, it does implicitly link the two.

I 5. That is at least, in the context of DM I6, all individual substances. It is hard, at this stage, to see any reason why this should not apply to corporeal substances too, if there are any. We might well also ask why this does not apply to aggregates, phenomena, and anything else in the created world. These are all, after all, effects of God.

I6. That said, I note that McRae argues that "An effect is not essentially an expression of its cause; that it is is a contingent fact discoverable in experience" (I976: 65), meaning by this that expressing its cause is not part of the definition of 'effect'. 
Surely, one might think, one thing can act in a way that changes or gives rise to another, without the second having anything like the structure of the first. Though discussion of examples is complicated, in the Leibnizian context, by Leibniz's denial that there are any genuine causal relations between created substances, ${ }^{17}$ there is an interpretive puzzle here-one that remains even if we are not attached to the standard reading of expression. ${ }^{\mathrm{I}}{ }^{8}$ In this section I explore three readings of Leibniz's motivation for claiming that substances express their causes.

\section{Explanation I: expression and knowledge}

Those discussing Leibniz's views about expression have often referred to the lateI670s note "What is an Idea?" (A: 6.4, I369-7I/L: 207-8). One might hope that it would provide some illumination of the current issue. In the course of his discussion there, Leibniz does say things that might appear to help. In particular, he says that "every entire effect represents the whole cause, for I can always pass from knowledge of such an effect to knowledge of its cause" (A: 6.4, I37 I/L: 208). ${ }^{19}$ So if we have knowledge of an "entire effect" then we will be able to acquire knowledge of the "whole cause" of that effect. That suggests the following argument.

I. If one has knowledge of an (entire) effect, one can acquire knowledge of its (whole) cause.

2. That could only be the case if the effect represented the cause. So

3. All (entire) effects represent their (whole) causes.

Some details about 'entire' and 'whole' aside, this gets us close to the Discourse's claim that effects express their causes. However, it is relatively unhelpful as an explanation of why Leibniz held that view in the Discourse.

This is a text from several years before the Discourse, and it is not so clear that the details of Leibniz's views of expression (in particular, expression of God) were all that stable over time. Moreover, the argument seems not to tell us why effects express their causes, even if it does show us that it must be the case that they do. Now, premise I here might gain some motivation from widespread views

I7. The expression of this point is complicated by the sorts of cause explained in DM I 5 and discussed in section I.I above. Why not call those 'genuine causal relations'? Well, one might, but then there will be a further sense of 'cause' involved in the observation that Leibniz thinks the relations between created substances involve harmony rather than causation.

I8. This does suggest the question of whether we should expect Leibniz to have a reason for premise I above that would be potentially plausible to people with different views about what actually causes what, or merely a reason to accept the premise given Leibniz's views about what causes what.

19. Leibniz uses the language of representation rather than expression here, but in this context appears to be using these terms interchangeably. 
of knowledge and understanding that adhere to or approximate the slogan that to know is to know through causes. If one really had knowledge of the effect, the reasoning might go, that would involve knowing the cause and how it produced the effect. But if we think in this way, then the crucial fact appears to be about what knowledge and explanation are, and appears not to require any representationor expression-of the cause by the effect. The one who knows the effect must know the cause, but the effect itself does not need to know or represent or express it-at least, no reason why it must is given here. Thus, all in all, this appears not to be a terribly helpful explanation of why, in I686, Leibniz thought that all effects expressed their causes.

\section{Explanation 2: the cause-effect relation as a special case of expression}

Garber (2009: 216-24) discusses expression, and argues that "the cause/effect relation is a special case of the expression relation" (2 I 8), basically because expression requires a "constant and fixed" relationship, and causation is such a relationship. ${ }^{20}$ Thinking along this sort of line, we might construct another argument for the claim that effects express their causes.

I. The relation of expression holds between two things, A and B, when there is a regular relation between them.

2. The cause-effect relation is a regular relation between two things. So

3. When two things stand in the cause-effect relation, the relation of expression also holds between them. So

4. All effects express their causes.

Evaluating this is largely a matter of deciding whether causation meets Leibniz's criteria for a regular relation. It does not seem to be one of his usual examples. ${ }^{21}$ And to take causation to be appropriately regular is to make certain assumptions about causation, which it would be helpful, at least, to see filled in. In this connection it is worth noting that efficient causation, at least, seems not to be structurepreserving in the way that expressing relations are often taken to be. ${ }^{22}$ Overall,

20. See also McRae's claim that "in any cause-effect relations, where it is not thoughts which are expressed, it is possible to see that ordered connection between what expresses and what is expressed to be the sort described by Leibniz" (I976: 24).

2I. Though he does, as in DM I 5 , attempt to explain apparent causal relationships, as between two finite substances, in terms of expression. And the expression of God is not a usual example of expression either.

22. I would not in general want to assume that expression must be structure-preserving, or that the causation being discussed here must be efficient causation-but there is more to say about what is going on. I address closely related issues in section 4 below, where I consider the connection between 
there is enough complexity here that we should not take this reading to offer an easily acceptable, simple explanation. And there is another, and good, explanation available.

\section{Explanation 3: expression and complete concepts}

There are yet other Leibnizian reasons to think that an effect will express its cause. Indeed, I suggest that we can find a complete Leibnizian reason for the view in the Discourse itself.

Consider the views expressed in DM 8 about predication, complete concepts, etc. ${ }^{23}$ There Leibniz says that "the nature of an individual substance or of a complete being is to have a notion so complete that it is sufficient to contain and to allow us to deduce from it all the predicates of the subject to which this notion is attributed". Among the predicates attributed to individual substances will be some that relate it to God. Indeed, these will include predicates about the substance's being an effect of God. Given this, we can reason as follows.

There will be true claims of the form ' $\mathrm{S}$ is $\mathrm{P}$ ' that relate any substance to God. Suppose for instance that 'P' is 'an effect of God'. For any created substance this will be true. Thus, by the view about concepts explained in DM 8, an effect of God will be contained in the complete concept of every substance. ${ }^{24}$ Moreover-given the reasoning at the end of DM 8-there will be marks and traces in each substance corresponding to this predicate. These marks and traces in the substance are naturally understood as the substance's representations of the things described by the corresponding predicates. So we can at least say that each individual substance represents God.

Thus we can see why Leibniz would say that all substances express God. Moreover, if substances had any causes other than God, we could show that the sub-

the relationships of expression and emanation-though similarly, I would not want to assume that all the claims about effects expressing causes are just about emanative causation.

23. There is a lot of literature on this topic. For a shorter account, see Wilson (I989: 88-98).

24. This relies on taking the view about predication and truth to be, as it is stated to be in DM 8 , a story about all predication. But one might think it does not apply to predicates about existence, creation, and actuality, such as 'an effect of God'. For one thing, sometimes Leibniz talks about God examining complete concepts and making decisions about creation, in a way that suggests creation does not change the concept. This connects to his saying to Arnauld that "the notion of an individual includes considered as possible what, in fact, is true, that is, considerations related to the existence of things" (G: 2, 39/AG: 70). Though various technicalities arise here, one might at first approximation address this, in my example, by taking the complete concept to contain a possible effect of God rather than an effect of God. This would still get us to the conclusion that all substances express God. More generally, Leibniz appears to have had two rather different ways of approaching complete concepts-by thinking about creation and divine understanding, and by thinking about predication and truth - and we might ask whether these each led Leibniz to precisely the same place. On theological and non-theological approaches to complete concepts, see Di Bella (2005: in particular 265-74).

Ergo $\cdot$ vol. 2, no. 4 2015 
stances would express them too, by similar reasoning. Thus, we could understand the view that all substances express their causes as a consequence of Leibniz's views about substances and language. Moreover, it would be a reason why substances, in particular, express their causes.

This sort of reasoning also fits well with Leibniz's claim that we, and other individual substances, express everything, including, but not just, God. For the complete concept view leads to thinking that all individual substances (including ourselves) have concepts that represent everything else.

As a reading of the Discourse, or of Leibniz's views in 1686 , this approach has the advantage that the resources for explaining why Leibniz thought that substances express their causes are contained in the text itself. Seeing the view that all substances express God as grounded in Leibniz's views about predication also fits nicely with the view appearing in Leibniz's I 689 "Primary Truths" essay, which attempts to ground many Leibnizian views in his views about language. ${ }^{25}$ This reading might also help explain why the expression of God is not a persistent feature of Leibniz's statements about substances-as the DM 8 view tends to play less of an explanatory role over time, this view of all substances as expressing God might naturally tend to disappear with it. ${ }^{26}$

On the other hand, the importance of expressing causes might appear to be minimal on this reading. Substances turn out to express causes simply because they express everything that stands in any relation to them. ${ }^{27}$ That is somewhat at odds with Leibniz's apparent view that causation is distinctive here. So this understanding of why Leibniz says that substances express their causes is not unproblematic, despite its notable advantages.

\section{Do Only Minds Express God?}

Above, we have seen Leibniz arguing that all individual substances express God. But as we have also seen, he seems not to have said this consistently, even within the Discourse.

Consider the last four sections of the Discourse, which focus on the difference between minds and other substances. Even here Leibniz continues to suggest that

25. See note 14 above.

26. See Garber's comment on a related issue: "While the claim that individual substances have complete individual concepts is one of the enduring theses of Leibniz's philosophy, and while Leibniz continues to hold the non-communication thesis to the end of his life, the argument for it from the CIC [Complete Individual Concept] seems to drop out of his repertoire rather quickly, by the early or mid-I690s" (2009: I98-9).

27. Any relation, not just a regular one, whatever exactly that is. That said, it is unclear if we can find a Discourse-appropriate distinction between regular relations and relations in general, given the view of DM 6 that all arrangements have regular rules, even if we cannot see what they are. 
all substances express God. Thus in DM 35 we are told that "the whole nature, end, virtue, and function of substance is merely to express God and the universe". But in DM 36 he appears to deny that all substances express God, for there he says that "other substances express the world rather than God, while minds express God rather than the world" (DM 36). Something very similar is in the summary of DM 35, and in at least two of Leibniz's subsequent letters to Arnauld (A: 2.2, $60,257)$. This appears to be the view that only some individual substances, minds, express God. So which is it? Do only some individual substances express God, or all of them? What led Leibniz to assert, apparently, that only minds express God?

A few years before the Discourse, Leibniz talked of expression of God in the "Conversation du Marquis de Pianese et du Pere Emerey Emerite". ${ }^{28}$ There he said that minds, which are infinitely more noble than other things, "express the perfection of their creator in a quite different way than other creatures, which are incapable of this elevation, do". ${ }^{29}$ Thus we find minds expressing God, and some difference between the way they express God and the way other substances do. $3^{\circ}$ Indeed even in the Discourse there are hints that that is what is going on. Thus Leibniz says in DM 35 that "minds are the most perfect beings and best express divinity", suggesting that other beings also express divinity, just not as well. But still, there are more strikingly contrasting passages, which do seem to give rise to a contradiction.

I suggest that, if we look at this part of the Discourse, we can see that Leibniz has a second way of talking about substances' expression of God, which is not grounded in their being caused by God. Perhaps seeing this second sense of expression will help us understand why Leibniz makes the striking claims. One theme in the discussion is that minds are made in God's image. ${ }^{3 \mathrm{I}}$ Thus minds have a sort of resemblance to God that the other substances lack. For this reason we might say that minds express God, whereas other substances do not.

The central ways in which minds are said, in the Discourse, to be particularly

28. Mercer describes an even earlier view, of April I676, thus: "Each creature expresses the same essence, but in a slightly different way; that is, each creature will somehow instantiate all the attributes of God" (I996: I07), citing "On the Origin of Things from Forms" (A: 6.3, 517-22/DSR: $74-82)$.

29. That is: "je suis asseuré que les esprits ont esté bien ordonnés preferablement à toutes les autres choses, qu'ils passent infiniment en noblesse, puisqu'ils expriment la perfection de leur createur d'une toute autre maniere que le reste des creatures incapables de cette elevation" (A: 6.4, 227I; my translation).

30. For another variation on the theme see the "Specimen inventorum de admirandis naturae generalis arcanis", which the Academy editors date as I688(?), and which Parkinson (1974) notes contains several themes familiar from the Discourse. In particular: "Quin imo cum Mens unaquaeque sit divinae imaginis expressio (nam dici potest caeteras substantias magis universum exprimere, Mentes magis Deum)" (A: 6.4, I624).

3I. That minds are made in the image of God is not something just emphasized in the Discourse. See Nelson (2005: 283), emphasizing the importance of what he calls the "God's image" requirement.

Ergo • vol. 2, no. 4 • 2015 
like God all involve knowledge. Thus in DM 34 we are told that minds know "what they are" (they have knowledge of the self as a persisting thing), they know "what they do", and they can "discover necessary and universal truths". In DM 35 minds are described as intelligent substances that "express the universe with the knowledge of what they are doing" and "are capable of knowing great truths about God and the universe". And in DM 36 a mind "does not merely express the world but it also knows it and it governs itself after the fashion of God". It can "can serve him [God] freely and act with knowledge in imitation of the divine nature". This possession of knowledge is related to minds' being the created substances that possess moral qualities. Knowledge is, for Leibniz, a perfection. God has this-and all the other perfections- to the highest degree, but minds have more of it than other finite substances do. ${ }^{32}$ Thus they resemble God more greatly. ${ }^{33}$

Looking at these examples suggests that this kind of expression involves resembling by having a different (lesser) degree of some feature. This differs from a structural similarity-the point is not that created minds somehow have the same overall structure as God's mind, but rather that they have this one feature, knowledge, to a lesser degree. ${ }^{34}$

Although this expression involves a matter of degree, one might nevertheless hope to find a sharp distinction here between minds and other created substances. The picture would be that minds have less knowledge than God, but other substances have no knowledge at all, or no knowledge of a certain sort. In a related way, one might look to find in the Discourse a version of what Mark Kulstad, citing a letter Leibniz sent to Arnauld in I687, calls "the three-part hierarchy, which, in various forms, became a staple of Leibniz's later writings, namely, that of 'natural perception, animal feeling, and intellectual knowledge"' (I991: 75).35 And Leibniz, in $\mathrm{DM} 35$, does contrast minds with "natures, which are either brutish and incapable of knowing truths or completely destitute of sensation and knowledge", suggesting a three-part hierarchy of substances that know, substances that sense, and other, lower substances. ${ }^{6}$ Seeing that does give us some reason why Leibniz would say that-in this sense of 'expression'—minds express God and other substances

32. DM I tells us that knowledge is a perfection, and DM 5 that minds have "perfections", which "consist in their virtues". Later, in $\mathrm{DM}_{3} 6$, minds are said to be the "most perfectible" substances. See also Jolley (2004: I35) on minds" "distinctive perfection of knowledge".

33. Bolton (2013: $\left.\mathrm{I}_{7} \mathrm{n}_{3} 6\right)$ connects the themes of perfection and expression of God, referring to a text from I677 (G: I, 225): "Leibniz sometimes defines 'perfection' as 'quantity of essence,' which would seem to be a function of the extent to which an essence expresses the infinite perfection of God".

34. One might perhaps still want to regard this as a case of a regular relation between the expressing and expressed things, but it is not the usual case.

35. Kulstad is discussing Leibniz's letter to Arnauld of 9 October I 687 (A: 2.2, 238-6I/L $338^{-}$ $50)$.

36. The details of the distinctions between the kinds of substances are not, however, developed in detail here. See Kulstad (I99I: 76). 
do not. For minds resemble God in possessing a lower degree of the perfection of knowledge, something that is lacking in the lower substances. Nevertheless, there remains a sense in which other substances also express God, even in this sense of 'expression'. For though natural perception and animal feeling are not knowledge, they are importantly similar to it. ${ }^{37}$ Though a substance that has perception and no knowledge is importantly unlike God, in lacking the perfection of knowledge, it still retains a (lower) degree of similarity to God, because of perception's similarity to knowledge..$^{8}$

Trying to pull this all together, it appears that there are two distinct theories of expression of God in the Discourse. The first is a causal theory of expression, holding that all substances express their causes. It appears, according to this theory, that all created substances express God equally well, for all are, equally, effects of God. The second is a theory that considers expression of God in terms of being a better or worse image of God. Thinking in this way, minds are better expressions of God than other substances are, for they, like God, possess the perfection of knowledge. 39

Still, what should we make of the striking formulation: minds expressing God rather than the world, other substances expressing the world rather than God? Even if we temper our reading somewhat-minds expressing God more than they express the world, other substances expressing the world more than they express God - it still does not sit well with Leibniz's other statements. ${ }^{40}$ However, one way to think about the formulation is as trying to convey what are the most striking facts about each sort of substance's expression of other things. After all, Leibniz introduces this formulation as something "we may say" (DM 36) rather than simply presenting it as a description. The most notable description of minds' expression is that they express God-simply because being made in the image of God is such an important thing, and minds do this better than anything else does, in virtue of

37. Indeed Leibniz told Arnauld, in the I 687 letter cited above, that all three are species of the same genus, expression (A: 2.2, 240/L 339). Moreover, in DM 9 we find Leibniz saying that "every substance bears in some way the character of God's infinite wisdom and omnipotence and imitates him as much as it is capable". That does not strictly contradict the claim that only minds have knowledge, but it does suggest that each substance possesses, in some way, wisdom.

38. One might speculate that the lack of a sharp distinction between minds and other substances in this regard is a result of the underdeveloped nature of Leibniz's views about the differences between them in general in I686 (here again see Kulstad's discussion). But it seems rather to be a consequence of Leibniz's view that they are all, in one way or another, perceiving substances.

39. Mercer introduces the helpful notion of a partial expression, which we might employ here: "for any essence E, whether infinite or finite ... there is a range of expressions of it, from partial to complete where a partial expression of $\mathrm{E}$ is a 'display of a property' of $\mathrm{E}$ and a complete expression is a display of every property of E" (I996: I08). A different account of partial expression is presented in Mercer (200I); see section 5 below.

40. Both because he clearly thinks minds do express the world, and because non-minds still express God, both by expressing their causes and by resembling him (albeit to a lesser degree than minds do). 
their possession of knowledge. Other substances are less notable in this way-but they still, as Leibnizian individual substances, possess the very notable feature of expressing the whole of the universe. So that, in their case, is something it is reasonable to emphasize. And that gets us to the striking formulation. ${ }^{4 \mathrm{I}}$

\section{Expression and Emanation}

There appear then to be two, largely distinct theories about expression of God presented in the Discourse. But to conclude my discussion, I want to consider a further Leibnizian idea that may connect them. This is the idea that created substances are emanations of God. The language of emanation is not prominent in the Discourse, but does occur there: "created substances depend on God, who preserves them and who even produces them continually by a kind of emanation" (DM I4). This short text presents three relationships between God and created substances: creation, preservation, and emanation.

To consider the relevance of the third relation, emanation, I begin from a summary by Christia Mercer, who argues that this is one of the sources of the Platonism in Leibniz's philosophy (2008: 226).42

The Theory of Emanative Causation claims that, for a being A that is more perfect than a being $B, A$ can emanate its attribute $f$-ness to $B$ in such a way that neither A nor A's f-ness is depleted in any way, while B has f-ness, though in a manner inferior to the way it exists in A. The emanative process is continual so that $\mathrm{B}$ will instantiate $\mathrm{f}$-ness if and only if $\mathrm{A}$ emanates $\mathrm{f}$-ness to it. The Supreme Being is in the creatures in the sense that it emanates its attributes to them; it remains transcendent from them because it neither loses anything in the emanative process nor gives them any part of itself. The crucial point to understand is that the attributes exist in the products in a manner inferior to the way in which they exist in the Divine. God has the form or Idea f perfectly; creature has it imperfectly (Mercer 2008: 228).43

4I. In this paper I do not consider the issue of minds' ability to express possibilia, something we can see briefly in the Discourse in DM 29. But we can see this as an aspect of the second theory-our minds resemble, and thus express, God in being able to think about possibilia.

42. For all that this is in a way Neoplatonic, there were also aspects of it in scholastic Aristotelianism. Both O’Neill (I993: 36-7) and Fouke (I994: I76-8I) show this sort of model being used by Aquinas.

43. O’Neill (I993: 32-5) and Fouke (I994: especially I77-8) provide similar accounts of the main aspects of this model of causation. O'Neill thinks that "the Neoplatonic influence model ... plays a central role in Leibniz's construction of influxus physicus" (I993: 35), i.e., in the construction of a view of causation (within nature) that Leibniz criticized. But one might grant that and still think 
Suppose one begins with a picture of substances as emanations of God. They will as a result all have the same features that God has, albeit in an imperfect or watered-down way. So the created substances, the effects of God, will also be guaranteed, by the nature of emanative causation, to resemble God. If we're talking about emanative causation, causation and resemblance go together. So, if we talk about emanative causation, expression as resemblance and expression of causes come together. Then, if we take Leibniz to have emanative causation in mind in the Discourse, we can see why he would say two apparently different things about expression-that effects express their causes, and that substances express God by resembling God. Thus we have an explanation for Leibniz's presenting his two different views about expression of God.

One might wonder whether Leibniz really had emanative, neo-Platonist notions in mind in the Discourse. The first and best reason to think that he did is simply that Leibniz more than once invokes emanation in the Discourse. In DM I4 we are told that "created substances depend upon God, who preserves them and who even produces them continually by a kind of emanation" and that "all individuals emanate continually" from God. The notion reappears in DM 32, where Leibniz says "that all other substances depend on God, in the same way as thoughts emanate from our substance". One can certainly ask questions about whether and how all the theoretical notions introduced in the Discourse fit together. Thus someone might perhaps argue that emanation does not fit well with the other notions introduced there-but one can hardly deny its presence. ${ }^{44}$ Leibniz's use of such neo-Platonic ideas in the Discourse also fits a broader pattern of his use of them. Nor is this use confined to early texts, such as those discussed by Mercer (200I).45 Lee (2004: 209-I2) argues persuasively that we can find Leibniz employing neo-Platonic notions of perfection, limitation and emanation in the mid

Leibniz was influenced by the emanative model in his picture of causal relations between God and the created world.

44. How, one might ask, could Leibniz remain committed to this picture, with its especially close link between God and created substances, while also being opposed to occasionalism? For, broadly speaking, the problem Leibniz sees with occasionalism is that it proposes too close a link between God and the activities of finite substances. However, even if one grants that the emanative influence of God is not importantly different from the influence of God seen in occasionalist systems, it would not be terribly surprising to find that Leibniz had, in the Discourse, conflicting commitments that he had not succeeded in reconciling. The persistence of the theme of emanation in later texts (see below) lends some support to the thought that this was a commitment he wanted to preserve and work into his overall view, even if it was not always clear how it fit in. Alternatively, one might follow Fouke, who argues that Leibniz's critique of occasionalism is grounded in the emanationist view, Leibniz thinking that "creatures have causal power precisely because they participate in God's power and because they are constituted of perfections received from and found in God" (2004: I 88).

45. On the other hand, in the c.I680 "Conversation du Marquis de Pianese et du Pere Emerey Emerite", cited above, an argument against an emanationist view of God is presented, that such a view makes it hard to love and honour God (A: 6.4, 2269). 
to late I69os. Similar notions are still at work in I7 I4, in Monadology 47-8 (G: 6, 6I4-5/AG: 2I9). ${ }^{46}$

The suggestion that thoughts about emanation are at work in the background of Leibniz's talk of expression of God in the Discourse, and tie together his two strands of thought about expression, is, I grant, a slightly speculative thought. And it would not resolve all the puzzles mentioned above, or completely unify the two views of expression. For instance, it does not clear up the issue of Leibniz's sometimes saying that only minds express God, for non-minds, as well as minds, are emanations of God. But it does help us see why the two theories might both be there. Emanative causation involves a certain resemblance between cause and effect. That resemblance is one ground for saying created substances express God. And a focus on emanative causation, with this resemblance involved, might help explain why Leibniz says that substances express their causes.

\section{Expression of God before and after the Discourse}

The theory of emanative causation thus provides a link between two apparently distinct approaches to the expression of God in the Discourse. I conclude, in this section, by looking briefly at how Leibniz thought about the expression of God in earlier and later texts. In particular, seeing a connection between expression and emanation opens up an intriguing possible connection between the Discourse and some earlier texts from 1676.

Mercer (200I: 427-36), in discussing those earlier texts, argues that they contain a different view of expression than the "mathematical and functional account that Leibniz came to use later" (Mercer 200I: 434 n. I64). On the I676 view of expression "S expresses an essence $E$ just in case $S$ is a partial representation of $\mathrm{E}$ which means (at least) that to understand $\mathrm{S}$ is equivalent to having a partial cognition of E" (Mercer 200I: 436). Moreover, in the I676 text, every substance expresses God: “because every created substance $S$ (and every state of $S$ ) contains the (selected) divine essence, $S$ (and every state of $S$ ) will be a partial expression of the divine essence" (Mercer 200I, 436).

If we think that emanation is playing the sort of role I have suggested in the Discourse, then we can in fact see something going on there that is very similar to what Mercer argues was going on in the 1676 texts. That sort of expression is indeed different from the "mathematical and functional" account that dominates discussions of expression. But that sort of account-call it mathematical, function-

46. Even if one does not agree with the strong claims of Fouke (2004) about the importance of such themes in Leibniz's later writings (from I686), he is surely correct to draw attention to the presence of such themes. 
al, or structural-is itself not easy to square with the Discourse's repeated talk of expression of God (however exactly we understand it). So it might well be sensible to take the extensive talk of expression of God in the Discourse as a holdover of an earlier view.

However, although the views about expression of God in the Discourse might seem to hark back to earlier themes, they might also seem not to be terribly long lasting. Thinking along similar lines, Catherine Wilson has said that "the claim that humans express God rather than the world does not seem to be a consistent theme of Leibniz's, and its appearance here [in DM 36] may represent a transitory moment of enthusiasm" (2005: I I9 n. 4). It does seem harder, as we move further away from the Discourse, to find Leibniz saying that all substances express God. As I speculated previously, perhaps this has to do with the connections between the expression of God view and Leibniz's views about language and complete concepts, which themselves appear less prominent over time. The other view, that minds express God in some special way, does have some later echoes. Not, perhaps, in the striking formulation in which they express God but do not express the universe-but then that was never the whole of Leibniz's view.

Consider just one case, that of what is probably still Leibniz's most famous later text, the Monadology. 47 There the language of expression appears to be confined to talk of substances expressing the universe. Thus Monadology 59 has "every substance expressing exactly all the others" (G: 6, 6I6/AG: 220). But late in the text we come to minds, and in particular the discussion of Monadology 83 . Here we find that "minds are also images of the divinity" in addition to being "living mirrors or images of the universe of creatures" (G: 6, 62I/AG: 223). This uses the language of images rather than that of expression. But it does seem to make a point familiar from the Discourse, that minds, like all other substances, represent the universe, but minds represent God in some distinctive way. Again, too, that distinctive feature of minds is connected to knowledge, minds being "capable of knowing the system of the universe" (G: 6, 62 I/AG: 223). That is not to say all the related thoughts are the same here as in the Discourse, but there does seem to be a continuity.

I do not, in this paper on the Discourse, attempt a complete account of the development of Leibniz's views on the expression of God. But perhaps we can begin to see some patterns. The I 676 view, on Mercer's reading, will tend to have all substances expressing God. As we have seen, the Discourse can seem equivocal about this, though it tends towards that view. By the Monadology there is a clearer singling out of minds alone as images of God.

47. This is not the only relevant later text. For example, Leibniz wrote to André Morell in I 698 that "As all minds are unities, it can be said that God is the primitive unity, expressed by all the others according to their capacity" (A: I.I 5, 560/SLT: 39). 


\section{Acknowledgments}

I thank those who participated in a discussion of these issues at http://philosophy modsquad.wordpress.com/20I3/I 2/O2/leibniz-on-expression-I/. I thank in particular Julia Jorati and Paul Lodge for further discussion, as well as their comments there. And I thank an anonymous referee for Ergo for their helpful report.

\section{Abbreviations}

A = Gottfried Wilhelm Leibniz (1923-). Sämtliche Schriften und Briefe. Akademie Verlag. Cited by series, volume, and page.

AG = Gottfried Wilhelm Leibniz (I989). Philosophical Essays. Trans. Roger Ariew and Daniel Garber. Hackett.

$\mathrm{DM}=$ Gottfried Wilhelm Leibniz ( ( 686). Discours de métaphysique [Discourse on Metaphysics]. In A: 6.4, I 529-88. Cited by section number, quoting the translation of AG: 35-68.

DSR = Gottfried Wilhelm Leibniz (I992). De Summa Rerum: Metaphysical Papers, I675-I676. Ed. G.H.R. Parkinson. Yale University Press.

$\mathrm{G}=$ Gottfried Wilhelm Leibniz (I875-90). Philosophische Schriften. Ed. Carl I. Gerhardt. Weidmannsche Buchhandlung. Cited by volume and page.

$\mathrm{L}=$ Gottfried Wilhelm Leibniz (1970). Philosophical Papers and Letters (2nd ed.). Trans. Leroy E. Loemker. Reidel.

SLT = Gottfried Wilhelm Leibniz (2006). The Shorter Leibniz Texts. Trans. Lloyd Strickland. Continuum.

$\mathrm{WF}=$ Gottfried Wilhelm Leibniz (1997). Leibniz's 'New System' and Associated Contemporary Texts. Trans. R.S. Woolhouse and Richard Francks. Clarendon.

\section{References}

Bolton, Martha Brandt (20I I). Leibniz's Theory of Cognition. In Brandon C. Look (Ed.), The Continuum Companion to Leibniz (I36-58). Continuum.

Bolton, Martha Brandt (2013). Change in the Monad. In Eric Watkins (Ed.), The Divine Order, the Human Order, and the Order of Nature (175-94). Oxford University Press. http://dx.doi.org/10.1093/acprof:oso/9780199934409.001.0001

Di Bella, Stefano (2005). The Science of the Individual: Leibniz's Ontology of Individual Substance. Springer. http://dx.doi.org/10.1007/1-4020-3260-9

Fouke, Daniel (I994). Emanation and the Perfections of Being: Divine Causation and the Autonomy of Nature in Leibniz. Archiv für Geschichte der Philosophie 76(2), I68-94. http://dx.doi.org/10.1515/agph.1994.76.2.168

Garber, Daniel (2009). Leibniz: Body, Substance, Monad. Oxford University Press. http:// dx.doi.org/10.1093/acprof:oso/9780199566648.001.0001 
Grosholz, Emily R. (200I). Theomorphic Expression in Leibniz's 'Discourse on Metaphysics'. Studia Leibnitiana 33(I), 4-I8.

Jolley, Nicholas (2004). Leibniz and the Excellence of Minds. In Massimiliano Carrara, Antonio-Maria Nunziante, and Gabriele Tomasi (Eds.), Individuals, Minds, and Bodies: Themes from Leibniz (I 25-40). Franz Steiner Verlag.

Kulstad, Mark (I977). Leibniz's Conception of Expression. Studia Leibnitiana 9(I), 55-76.

Kulstad, Mark (I99I). Leibniz on Perception, Consciousness, and Apperception. Philosophia.

Kulstad, Mark (2006). Leibniz on Expression: Reflections after Three Decades. In Herbert Breger, Jürgen Herbst, and Sven Erdner (Eds.), Einheit in der Vielheit (4I3-9). Gottfried-Wilhelm-Leibniz-Gesellschaft.

Kulstad, Mark, and Laurence Carlin (2013). Leibniz's Philosophy of Mind. In Edward N. Zalta (Ed.), The Stanford Encyclopedia of Philosophy (Winter 2013 Edition). http:// plato.stanford.edu/archives/win2or z/entries/leibniz-mind/.

Mates, Benson (1986). The Philosophy of Leibniz: Metaphysics and Language. Oxford University Press.

McRae, Robert (1976). Leibniz: Perception, Apperception, and Thought. University of Toronto Press.

Mercer, Christia (I996). The Platonism of Leibniz's New System of Nature. In R.S. Woolhouse (Ed.), Leibniz's New System (97-I I I). Olshki.

Mercer, Christia (200I). Leibniz's Metaphysics: Its Origins and Development. Cambridge University Press.

Mercer, Christia (2008). The Platonism at the Core of Leibniz's Philosophy. In Douglas Hedley and Sarah Hutton (Eds.), Platonism at the Origin of Modernity: Studies on Platonism and Early Modern Philosophy (225-38). Springer.

Nelson, Alan (2005). Leibniz on Modality, Cognition, and Expression. In Alan Nelson (Ed.), A Companion to Rationalism (282-30I). Blackwell.

O’Neill, Eileen (1993). Influxus Physicus. In Steven Nadler (Ed.), Causation in Early Modern Philosophy: Cartesianism, Occasionalism, and Preestablished Harmony (27-55). Pennsylvania State University Press.

Parkinson, G.H.R. (I974). Science and Metaphysics in Leibniz's 'Specimen Inventorum'. Studia Leibnitiana 6, I-27.

Perkins, Franklin (2004). Leibniz and China: A Commerce of Light. Cambridge University Press. http://dx.doi.org/10.1017/CBO9780511519994

Puryear, Stephen (2006). Perception and Representation in Leibniz (Doctoral dissertation, University of Pittsburgh).

Rutherford, Donald (I995). Leibniz and the Rational Order of Nature. Cambridge University Press. http://dx.doi.org/10.1017/CBO9781139172776

Simmons, Alison (200I). Changing the Cartesian Mind: Leibniz on Sensation, Representation and Consciousness. Philosophical Review IIO(I), 3I-75. http://dx.doi. org/10.1215/00318108-110-1-31

Sleigh, Robert C. (I990). Leibniz and Arnauld: A Commentary on their Correspondence. Yale University Press.

Swoyer, Chris (1995). Leibnizian Expression. Journal of the History of Philosophy 33(I), 65-99. http://dx.doi.org/10.1353/hph.1995.0009 
Wilson, Catherine (1989). Leibniz's Metaphysics: A Historical and Comparative Study. Princeton University Press.

Wilson, Catherine (2005). Compossibility, Expression, and Accommodation. In Donald Rutherford and J.A. Cover (Eds.), Leibniz: Nature and Freedom (I08-20). Oxford University Press. http://dx.doi.org/10.1093/0195143744.001.0001 